\title{
Occurrence, antimicrobial susceptibility, and pathogenic factors of Pseudomonas aeruginosa in canine clinical samples
}

\author{
Jasmine Hattab ${ }^{1}$ (D), Francesco Mosca1 (D), Cristina Esmeralda Di Francesco ${ }^{1}$ (D), Giovanni Aste ${ }^{1}$ (D), Giuseppe Marruchella ${ }^{1 D}$, \\ Pierluigi Guardiani² and Pietro Giorgio Tiscar $^{1}$ (D) \\ 1. Department of Veterinary Medicine, University of Teramo, Loc. Piano d'Accio, 64100, Teramo, Italy; 2. Veterinary Clinic \\ "Saline", Città Sant'Angelo, 65013, Pescara, Italy. \\ Corresponding author: Francesco Mosca, e-mail: fmosca@unite.it \\ Co-authors: JH: jhattab@unite.it, CED: cedifrancesco@unite.it, GA: gaste@unite.it, GM: gmarruchella@unite.it, \\ PG: clinicaveterinariasaline@gmail.com,PGT: pgtiscar@unite.it \\ Received: 23-11-2020, Accepted: 08-03-2021, Published online: 23-04-2021
}

doi: www.doi.org/10.14202/vetworld.2021.978-985 How to cite this article: Hattab J, Mosca F, Di Francesco CE, Aste G, Marruchella G, Guardiani P, Tiscar PG (2021) Occurrence, antimicrobial susceptibility, and pathogenic factors of Pseudomonas aeruginosa in canine clinical samples, Veterinary World, 14(4): 978-985.

\begin{abstract}
Background and Aim: Pseudomonas aeruginosa is a relevant opportunistic and difficult to treat pathogen due to its widespread environmental diffusion, intrinsic resistance to many classes of antimicrobials, high ability to acquire additional resistance mechanisms, and wide range of pathogenic factors. The present study aimed to investigate the prevalence of $P$. aeruginosa in canine clinical samples, the antimicrobial susceptibility against antipseudomonal antibiotics, and the presence of extracellular pathogenic factors of the isolates, as well as their ability to produce biofilm.

Materials and Methods: Overall, 300 clinical specimens from dogs with pyoderma or abscesses $(n=58)$, otitis $(n=59)$, and suspected bladder infection $(\mathrm{n}=183)$ were analyzed by standard bacteriological methods. P. aeruginosa isolates were tested for their antimicrobial susceptibility by disk and gradient diffusion methods to determine the minimum inhibitory concentrations. The ability of the isolates to produce biofilm was investigated by a microtiter plate assay, while virulence genes coding for elastase (lasB), exotoxin A (toxA), alkaline protease (aprA), hemolytic phospholipase $\mathrm{C}(\mathrm{plcH})$, and exoenzyme $\mathrm{S}(\operatorname{Exo} S)$ were detected by polymerase chain reaction method.

Results: A total of 24 isolates of $P$. aeruginos $a$ were found in clinical specimens (urine $\mathrm{n}=3$, skin/soft tissue $\mathrm{n}=6$, and ear canal $n=15$ ). No resistance was found to ceftazidime, gentamicin, aztreonam, and imipenem (IMI), while low levels of resistance were found to enrofloxacin (ENR) (4.2\%) and piperacillin-tazobactam (8.3\%). However, $41.7 \%$ and $29.2 \%$ of the isolates showed intermediate susceptibility to ENR and IMI, respectively. Disk and gradient diffusion methods showed high concordance. The majority of the isolates revealed a weak $(33.3 \%)$ or intermediate $(45.8 \%)$ ability to form biofilm, while the strong biofilm producers $(20.8 \%)$ derived exclusively from the ear canal samples. All isolates $(100 \%)$ were positive for lasB, aprA, and plcH genes, while exoS and toxA were amplified in $21(87.5 \%)$ and $22(91.7 \%)$ isolates, respectively.

Conclusion: In the present study, P. aeruginosa isolates from canine clinical samples were characterized by low levels of antimicrobial resistance against antipseudomonal drugs. However, the high presence of isolates with intermediate susceptibility for some categories of antibiotics, including carbapenems which are not authorized for veterinary use, could represent an early warning signal. Moreover, the presence of isolates with strong ability to produce biofilm represents a challenge for the interpretation of the antimicrobial susceptibility profile. In addition, the high prevalence of the extracellular pathogenic factors was indicative of the potential virulence of the isolates.
\end{abstract}

Keywords: antimicrobial susceptibility, biofilm, dog infection, extracellular pathogenic factors, Pseudomonas aeruginosa.

\section{Introduction}

Pseudomonas aeruginosa is a Gram-negative, rod-shaped, non-glucose-fermenting aerobic bacterium that is widely distributed in environment [1]. It represents an opportunistic pathogen in dogs, mainly involved in ear canal and soft-tissues infections [2] and less commonly in urinary tract infection [3]. $P$. aeruginosa is naturally resistant to many classes of antimicrobial drugs due to intrinsic mechanisms,

Copyright: Hattab, et al. Open Access. This article is distributed under the terms of the Creative Commons Attribution 4.0 International License (http://creativecommons.org/licenses/by/4.0/), which permits unrestricted use, distribution, and reproduction in any medium, provided you give appropriate credit to the original author(s) and the source, provide a link to the Creative Commons license, and indicate if changes were made. The Creative Commons Public Domain Dedication waiver (http://creativecommons.org/ publicdomain/zero/1.0/) applies to the data made available in this article, unless otherwise stated. such as low outer membrane permeability [4], constitutive efflux pump systems [5], and high basal expression of chromosomal AmpC $\beta$-lactamase [6]. Hence, therapeutic options for $P$. aeruginosa are limited and only a few antibiotics are useful as antipseudomonal drugs, most of them not licensed for veterinary use. In addition, $P$. aeruginosa can rapidly acquire resistance through overexpression of efflux pumps [7], loss of functionality of porins [8], mutational changes of the antibiotic targets [9], and expression of a wide range of $\beta$-lactamases [10]. Therefore, $P$. aeruginosa can achieve resistance to each antimicrobial class through single or multiple mechanisms [11].

The worldwide emerging of resistant strains represents a serious threat for both human and animal health, considering the human-pet relationship as a 
critical issue for the transmission of clinically significant multidrug-resistant bacteria [12].

The present study aimed to investigate the prevalence of $P$. aeruginosa in canine clinical samples, the antimicrobial profile, and the presence of extracellular pathogenic factors of the isolates, as well as their ability to produce biofilm.

\section{Materials and Methods}

\section{Ethical approval}

Ethical approval was not needed since the present study was performed on diagnostic samples collected during the routine veterinary activities and submitted to the bacteriological investigation for diagnostic purpose.

\section{Samples, study period, and bacteriological investigation}

Overall, 300 clinical specimens from dogs with pyoderma or abscesses $(n=58)$, otitis $(n=59)$, and suspected bladder infection $(\mathrm{n}=183)$ were analyzed from May 2019 to July 2020. The specimens were non-duplicate and they were presumed to be epidemiologically non-related since they came from different animals, different families, presented different sampling dates, and originated from different locations. Samples were cultivated aerobically on 5\% sheep blood agar and MacConkey agar at $36^{\circ} \mathrm{C}$ for 24-48 h. A sample was considered positive if the bacterial growth was significant, both as pure culture or mixed microbial flora with dominance of one bacterial species. Subcultures of the positive samples were obtained using tryptone soya agar, then bacteria were Gram-stained and tested for catalase and oxidase. Confirmation of $P$. aeruginosa isolates was performed using a commercial biochemical identification system (API ${ }^{\circledR} 20$ NE, BioMerieux, France).

\section{Antimicrobial susceptibility testing (AST) of P. aeru- ginosa isolates}

Colonies of $P$. aeruginosa were suspended in normal sterile saline solution at optical density (OD) of 0.1 , measured through spectrophotometer at $595 \mathrm{~nm}$. The suspensions were swabbed on Mueller-Hinton agar (MHA). AST was performed by gradient diffusion method (Mic Test Strip ${ }^{\mathrm{TM}}$, Liofilchem, Italy), and after incubation at $36^{\circ} \mathrm{C}$ for $18 \mathrm{~h}$, the minimum inhibitory concentrations (MICs) of gentamicin $(\mathrm{CN})$, enrofloxacin (ENR), ceftazidime (CAZ), imipenem (IMI), aztreonam (ATM), and piperacillin-tazobactam (TZP) were determined for each isolate. The antimicrobial concentration range was $0.016-256 \mu \mathrm{g} / \mathrm{mL}$ for $\mathrm{CN}$, ATM, CAZ, and TZP and $0.002-32 \mu \mathrm{g} / \mathrm{mL}$ for ENR and IMI. Specific Clinical and Laboratory Standards Institute interpretative criteria for $P$. aeruginosa were considered to categorize each isolate as susceptible, intermediate, or resistant. In particular, human breakpoints were adopted for CAZ, IMI, and ATM [13], and veterinary breakpoints for CN, ENR, and TZP [14]. For each antibiotic, $\mathrm{MIC}_{90}$ and $\mathrm{MIC}_{50}$ values were defined as the lowest concentration at which 90 and $50 \%$ of the isolates were inhibited, respectively. The results obtained from the gradient diffusion method were compared to the results of the disk diffusion method that was performed using the same bacterial inoculum [15]. Inhibition zone diameters on MHA were measured after incubation at $36^{\circ} \mathrm{C}$ for $18 \mathrm{~h}$ and the categories were elaborated according to human breakpoints for CAZ $(30 \mu \mathrm{g})$, IMI $(10 \mu \mathrm{g})$, and ATM $(30 \mu \mathrm{g})$ [13] and to veterinary breakpoints for CN $(10 \mu \mathrm{g})$ and ENR $(5 \mu \mathrm{g})$ [14]. P. aeruginosa ATCC $^{\circledR}$ (USA) 27853 was used for quality control test. Considering the disk diffusion method as the reference standard, we classified the discrepancies between both methods into three categories, corresponding to very major (false-susceptible gradient diffusion test result), major (false-resistance gradient diffusion test result), and minor (difference in one interpretation category) [16].

\section{Phenotype screening of $\beta$-lactamase production}

The isolates with intermediate/resistant profile to one or more $\beta$-lactams were tested by combination disk tests for the detection of AmpC $\beta$-lactamase, extended-spectrum $\beta$-lactamases (ESBLs), and metallo- $\beta$-lactamases (MBLs). Bacterial isolates were suspended in normal sterile saline solution at $0.1 \mathrm{OD}_{595}$ and then swabbed on MHA.

\section{Phenotype screening of AmpC overproduction}

According to the method commonly used in Enterobacteriaceae [17], disks containing CAZ (CAZ $30 \mu \mathrm{g})$ and cefotaxime (CTX $30 \mu \mathrm{g}$ ) alone and in combination with cloxacillin were placed on MHA. The test was considered positive if the inhibition zone diameters of both cephalosporins plus cloxacillin were $\geq 5 \mathrm{~mm}$ larger than cephalosporins alone.

\section{Phenotype screening of ESBLs}

A previously described method for Enterobacteriaceae was adopted [13] with some modifications [18]. Disks containing CAZ (CAZ $30 \mu \mathrm{g}$ ) and cefotaxime (CTX $30 \mu \mathrm{g}$ ) alone and in combination with clavulanic acid $(10 \mu \mathrm{g})$ were placed on MHA containing cloxacillin at $250 \mu \mathrm{g} / \mathrm{mL}$. The test was considered positive if the inhibition zone diameters of both cephalosporins plus clavulanic acid were $\geq 5 \mathrm{~mm}$ larger than cephalosporins alone.

\section{Phenotype screening of MBLs}

As previously described [19], disks containing IMI $(10 \mu \mathrm{g})$ alone and in combination with EDTA $(750 \mu \mathrm{g})$ were placed on MHA containing cloxacillin at $250 \mu \mathrm{g} / \mathrm{mL}$. The test was considered positive if the inhibition zone diameter of IMI plus EDTA was $\geq 7 \mathrm{~mm}$ larger than IMI alone.

\section{Biofilm production}

Biofilm production was assessed by microtiter plate assay, as previously described [20,21]. P. aeruginosa cultures were inoculated into Luria Bertani (LB) broth to create a suspension with $\mathrm{OD}_{595}$ of 0.1 and $200 \mu \mathrm{L}$ of each isolate were then placed in triplicate into 96-well polystyrene microtiter plate. After 
incubation for $48 \mathrm{~h}$ at $36^{\circ} \mathrm{C}$ under static condition, the supernatants of the wells were transferred to empty wells and their $\mathrm{OD}_{595}$ values were measured. Then, the wells containing potential biofilm were kindly washed 3 times and the plate was dried at $60^{\circ} \mathrm{C}$ for $1 \mathrm{~h}$. Biofilms were stained with $200 \mu \mathrm{L}$ of a crystal violet solution $(0.1 \% \mathrm{w} / \mathrm{v})$ for $15 \mathrm{~min}$ at room temperature $\left(25^{\circ} \mathrm{C}\right)$ and the wells were washed 3 times to remove the excess stain. The microplate was air-dried, and for each well, the stained biofilms were solubilized with $200 \mu \mathrm{L}$ ethanol (95\%). After $15 \mathrm{~min}$ at room temperature $\left(25^{\circ} \mathrm{C}\right)$, the OD values of each well were measured at $570 \mathrm{~nm}$. The wells containing non-inoculated LB broth represented the negative control and the relative OD values were subtracted to the OD values of the wells containing bacterial samples. Biofilm index (BI) of each isolate was calculated as the $\mathrm{OD}_{570} /{ }_{595}$ ratio, reflecting the proportion between biofilm production and planktonic growth. Based on the mean BI values obtained from four replicate experiments, each isolate was classified into three categories, corresponding to strong $(\geq 2)$, intermediate (1-2), and weak biofilm producer $(\leq 1)[22]$.

\section{DNA extraction and pathogenic factors detection}

DNA extraction was performed by QIAamp DNA Mini Kit (Qiagen, Germany) according to the manufacturer's instructions. Virulence genes coding for elastase $(\operatorname{las} B)$, exotoxin A (tox $A)$, alkaline protease (aprA), hemolytic phospholipase $\mathrm{C}(\mathrm{plcH})$, and exoenzyme $\mathrm{S}(E x o S)$ were detected by polymerase chain reaction (PCR) method, as previously reported $[23,24]$ (Table-1).

PCR products were visualized in $1.5 \%$ agarose gel by means of ultraviolet transilluminator. To confirm the specificity of the results, the amplified products of each gene were randomly selected, purified, submitted to sequencing, and further used as positive controls. For negative controls, water was added instead of DNA template.

\section{Results}

Prevalence of $\boldsymbol{P}$. aeruginosa in canine clinical samples

A total of $24 P$. aeruginosa isolates were found in positive samples from skin/soft tissue $(6 / 39,15.4 \%)$, ear canal $(15 / 46,32.6 \%)$, and urine $(3 / 72,4.2 \%)$. Pure cultures of $P$. aeruginosa were observed in all the urine samples. The majority of the samples from skin/soft tissue and ear canal showed pure culture of $P$. aeruginosa, while few samples showed a polymicrobial flora which was characterized by the strong dominance of $P$. aeruginosa.

\section{Antimicrobial profile}

No resistance was found to CAZ, CN, ATM, and IMI, while low levels of resistance were found to ENR $(\mathrm{n}=1 / 24,4.2 \%)$ and TZP $(\mathrm{n}=2 / 24,8.3 \%)$. However, a high number of isolates showed intermediate susceptibility to ENR ( $\mathrm{n}=10,41.7 \%$ by disk diffusion method; $\mathrm{n}=11,45.8 \%$ by gradient diffusion method) and IMI $(n=7 / 24,29.2 \%)$. A high degree of correlation was found between disk and gradient diffusion methods, and only two minor discrepancies relative to ENR and $\mathrm{CN}$ were recorded. In both cases, the gradient diffusion method showed an intermediate response while disk diffusion method revealed a susceptible profile (Table-2).

\section{Phenotype screening of $\boldsymbol{\beta}$-lactamase production}

Five isolates were positive to AmpC $\beta$-lactamase test. Three of them (79-19, 50-20, and 52-20) were exclusively characterized by intermediate susceptibility to TZP, while two isolates (72-20 and 86-20) showed resistance to TZP and intermediate response to CAZ. Another isolate (60-20) showed an intermediate response against TZP, but it resulted negative to AmpC test; differently from the others, it was characterized by a reduced susceptibility to other $\beta$-lactams and also to ENR. No isolate was found positive for ESBLs and MBLs (Table-3).

\section{Biofilm production}

Five isolates (20.8\%) were classified as strong biofilm producers, while $8(33.3 \%)$ and $11(45.8 \%)$ isolates were weak and intermediate biofilm producers, respectively. Among the strong producers, all isolates derived from the ear canal samples of the animals suffering otitis (Table-4).

\section{Molecular detection of pathogenic factors}

All isolates $(\mathrm{n}=24,100 \%)$ were positive for las $B$, aprA, and $\mathrm{plcH}$ genes, while exoS and toxA were

Table-1: Primers and protocols used for PCR detection of the virulence genes.

\begin{tabular}{|c|c|c|c|c|c|c|}
\hline Gene target & Sequences $\left(5^{\prime}-3^{\prime}\right)$ & Amplicon size (bp) & Denaturation & Amplification & Final extension & Ref \\
\hline lasB-F & GGAATGAACGAAGCGTTCTC & 300 & \multirow[t]{3}{*}{$94^{\circ} \mathrm{C}-3 \mathrm{~min}$} & 30 cycles & $72^{\circ} \mathrm{C}-5 \mathrm{~min}$ & \multirow[t]{2}{*}{ [23] } \\
\hline $\begin{array}{l}\text { TasB-R } \\
\text { toxA-F }\end{array}$ & $\begin{array}{l}\text { GGICLAGIAGIAGCGGIIGG } \\
\text { GGTAACCAGCTCAGCCACAT }\end{array}$ & \multirow{2}{*}{352} & & $55^{\circ} \mathrm{C}-60 \mathrm{~s}$ & & \\
\hline toxA-R & TGATGTCCAGGTCATGCTTC & & & $72^{\circ} \mathrm{C}-90 \mathrm{~s}$ & & \\
\hline plcH-F & GAAGCCATGGGCTACTTCAA & 307 & & & & \\
\hline plcH-R & AGAGTGACGAGGAGCGGTAG & & & & & \\
\hline exoS-F & CTTGAAGGGACTCGACAAGG & 504 & & & & \\
\hline exos-R & TTCAGGTCCGCGTAGTGAAT & & & & & \\
\hline aprA-F & АCСCTGTCCTATTCGTTCC & \multirow[t]{4}{*}{140} & $94^{\circ} \mathrm{C}-5 \mathrm{~min}$ & 30 cycles & \multirow[t]{4}{*}{$72^{\circ} \mathrm{C}-5 \mathrm{~min}$} & \multirow[t]{4}{*}{ [24] } \\
\hline aprA-R & GATTGCAGCGACAACTTGG & & & $94^{\circ} \mathrm{C}-60 \mathrm{~s}$ & & \\
\hline & & & & $52^{\circ} \mathrm{C}-60 \mathrm{~s}$ & & \\
\hline & & & & $72^{\circ} \mathrm{C}-90 \mathrm{~s}$ & & \\
\hline
\end{tabular}

PCR=Polymerase chain reaction 
Table-2: Antimicrobial profiles of Pseudomonas aeruginosa by means of gradient diffusion method.

\begin{tabular}{|c|c|c|c|c|c|c|c|c|c|c|}
\hline \multirow[t]{2}{*}{ Antimicrobial } & \multicolumn{2}{|c|}{$\begin{array}{c}\text { MIC } \\
\text { breakpoint } \\
\left(\mu \mathrm{gL}^{-1}\right)\end{array}$} & \multirow[t]{2}{*}{ R (\%) } & \multirow[t]{2}{*}{ I (\%) } & \multirow[t]{2}{*}{$\begin{array}{c}\operatorname{MIC}_{50} \\
\left(\mu g^{-1}\right. \\
\left.\mathrm{mL}^{-1}\right)\end{array}$} & \multirow[t]{2}{*}{$\begin{array}{c}\operatorname{MIC}_{90} \\
\left(\mu g^{-1}\right) \\
\left.\mathbf{m L}^{-1}\right)\end{array}$} & \multirow{2}{*}{$\begin{array}{l}\% \text { agreement } \\
\text { with disk } \\
\text { diffusion } \\
\text { method }\end{array}$} & \multicolumn{3}{|c|}{$\begin{array}{l}\text { Number of isolates by } \\
\text { error category }\end{array}$} \\
\hline & $\leq \mathbf{S}$ & $\mathbf{R} \geq$ & & & & & & Very Major & Major & Minor \\
\hline Enrofloxacin & 0.5 & 4 & $1 / 24(4.2)$ & $11 / 24(45.8)$ & 0.5 & 2 & 95.8 & 0 & 0 & 1 \\
\hline Ceftazidime & 8 & 32 & $0 / 24(0)$ & $2 / 24(8.3)$ & 2 & 8 & 100 & 0 & 0 & 0 \\
\hline Imipenem & 2 & 8 & $0 / 24(0)$ & $7 / 24(29.2)$ & 2 & 4 & 100 & 0 & 0 & 0 \\
\hline Gentamicin & 2 & 8 & $0 / 24(0)$ & $5 / 24(20.8)$ & 2 & 4 & 95.8 & 0 & 0 & 1 \\
\hline Aztreonam & 8 & 32 & $0 / 24(0)$ & $1 / 24(4.2)$ & 4 & 8 & 100 & 0 & 0 & 0 \\
\hline Piperacillin-tazobactam & $8 / 4$ & $32 / 4$ & $2 / 24(8.3)$ & 4/24 (16.7) & 4 & 24 & N.A. & & & \\
\hline
\end{tabular}

For each antibiotic, the number and the relative percentage of intermediate (I) or resistant (R) isolates were reported, in combination with $\mathrm{MIC}_{50}$ and $\mathrm{MIC}_{90}$ values. In the last two columns, the percentage of agreement with the disk diffusion method and the number of errors between the two methods were indicated.

Table-3: Phenotype screening tests for $\beta$-lactamases in Pseudomonas aeruginosa.

\begin{tabular}{|c|c|c|c|c|c|}
\hline \multirow[t]{2}{*}{$\begin{array}{l}\text { Pseudomonas aeruginosa } \\
\text { isolates (internal nomenclature) }\end{array}$} & \multirow{2}{*}{$\begin{array}{l}\text { Response to } \\
\beta \text {-lactams (I or } \\
\text { R - MIC } \mu \mathrm{g} / \mathrm{mL})\end{array}$} & \multirow[t]{2}{*}{$\begin{array}{l}\text { Response to non } \beta \text {-lactams } \\
(I \text { or } R-M I C \mu g / m L)\end{array}$} & \multicolumn{3}{|c|}{$\begin{array}{c}\text { Phenotype screening for } \\
\beta \text {-lactamase }\end{array}$} \\
\hline & & & AmpC & ESBL & MBL \\
\hline $72-19$ & $\begin{array}{l}\text { CAZ (I-12) } \\
\text { TZP (R-64) }\end{array}$ & No & + & - & - \\
\hline $79-19$ & TZP (I-16) & No & + & - & - \\
\hline $82-19$ & IMI (I-4) & ENR (I-1) & - & - & - \\
\hline $50-20$ & TZP (I-24) & No & + & - & - \\
\hline $52-20$ & TZP (I-16) & No & + & - & - \\
\hline $60-20$ & $\begin{array}{l}\text { ATM (I-16) } \\
\text { IMI (I-4) } \\
\text { TZP (I-24) }\end{array}$ & $\operatorname{ENR}(\mathrm{R}->32)$ & - & - & - \\
\hline $65-20$ & IMI (I-6) & CN (I-4) & - & - & - \\
\hline $67-20$ & IMI (I-6) & No & - & - & - \\
\hline $80-20$ & IMI (I-4) & No & - & - & - \\
\hline $82-20$ & IMI (I-4) & $\begin{array}{l}\text { CN (I-4) } \\
\text { ENR (I-1) }\end{array}$ & - & - & - \\
\hline $84-20$ & IMI (I-4) & $\mathrm{CN}(\mathrm{I}-4)$ & - & - & - \\
\hline $86-20$ & $\begin{array}{l}\text { CAZ }(\mathrm{I}-16) \\
\text { TZP }(\mathrm{R}->256)\end{array}$ & No & + & - & - \\
\hline
\end{tabular}

For each isolate, the intermediate (I) or resistance (R) response to $\beta$-lactams and non- $\beta$-lactams was indicated, including the relative MIC value. $C A Z=C$ eftazidima, $T Z P=$ Piperacillin-tazobactam, IMI=Imipenem, $C N=G e n t a m i c i n$, ENR $=$ Enrofloxacin, $A T M=$ Aztreonam

Table-4: Distribution of Pseudomonas aeruginosa isolates based on their ability to produce biofilm and site of sampling.

\begin{tabular}{|c|c|c|c|c|}
\hline \multirow{2}{*}{$\begin{array}{l}\text { Ability to } \\
\text { produce } \\
\text { biofilm }\end{array}$} & \multirow{2}{*}{$\begin{array}{c}\text { Number } \\
\text { of isolates } \\
\text { and relative } \\
\text { percentage }\end{array}$} & \multicolumn{3}{|c|}{ Site of sampling } \\
\hline & & Urine & $\begin{array}{l}\text { Ear } \\
\text { canal }\end{array}$ & $\begin{array}{c}\text { Skin/soft } \\
\text { tissues }\end{array}$ \\
\hline Weak & $8 / 24(33.3 \%)$ & $0 / 3$ & $7 / 15$ & $1 / 6$ \\
\hline Intermediate & $11 / 24(45.8 \%)$ & $3 / 3$ & $3 / 15$ & $5 / 6$ \\
\hline Strong & $5 / 24(20.8 \%)$ & $0 / 3$ & $5 / 15$ & $0 / 6$ \\
\hline
\end{tabular}

amplified in $21(87.5 \%)$ and $22(91.7 \%)$ isolates, respectively.

\section{Discussion}

$P$. aeruginosa is a relevant opportunistic and difficult to treat pathogen due to its specific characteristics, such as the widespread environmental diffusion, the intrinsic resistance to many classes of antimicrobials, the high ability to acquire additional resistance mechanisms, and the wide range of virulence factors $[25,26]$. A low prevalence $(4.2 \%)$ of
$P$. aeruginos $a$ was found in the urine of dogs suffering bladder infection, according to other authors which isolated Pseudomonas spp. in 2\% [27], 1.3\% [28], and $3.7 \%$ [29] of canine urinary tract infections. Instead, a discrete presence $(32.6 \%)$ of $P$. aeruginosa was recorded in dogs with clinical signs of otitis, slightly higher if compared to the previous studies which reported a prevalence of $27 \%$ [30] and 23\% [31]. Furthermore, in the skin and soft-tissue specimens, we found a higher prevalence of $P$. aeruginosa $(15.4 \%)$ in comparison to the frequency isolation of $7.5 \%$ [30] and $10.6 \%$ [32] described by other studies.

The antimicrobial profiles of canine $P$. aeruginosa isolates are difficult to compare between different studies, due to many variables that represent a challenge for the harmonization of global data. In particular, antimicrobial methods used [33], interpretative criteria applied [34], body sites of sampling [35], geographical [36], and temporal differences [37] represent all variables that have to be taken into account. In the present study, the MICs values were determined by means of diffusion gradient method on agar, using 
a predefined antibiotic gradient strip. The previous studies on human clinical strains of $P$. aeruginosa showed that results obtained by gradient diffusion method correlated well with agar dilution [38], broth microdilution [39], and disk diffusion methods [40]. By comparing disk and gradient diffusion methods, no substantial discrepancies were observed in the present study, but only minor differences.

Specific veterinary breakpoints for $P$. aeruginosa were considered for CN, ENR, and TZP. Instead, human breakpoints were adopted for CAZ, IMI, and ATM, bearing well in mind that these antibiotics should be considered as last-resort options for human therapy (monobactams) or eventually recommended for a small number of infections (carbapenems, $3^{\text {rd }}$ generation cephalosporins) [41].

The widespread use of ENR in clinical practice of small animals has led to a continuous increase of resistant isolates of $P$. aeruginosa associated to dog infections $[37,42]$. In the past decade, high percentages of resistance to ENR were reported in Europe for $P$. aeruginosa, as well as described in Croatia (51\%) [43], Greece (44\%) [44], France (67\%) [45], and Italy (43\%) [46]. In the present study, only one isolate $(4.2 \%)$ was found to be resistant to ENR, showing a MIC $>32 \mu \mathrm{g} / \mathrm{mL}$. This finding could be intended as a positive consequence of the national plans that promoted the responsible use of antibiotics in the past years. In France, the resistance to fluoroquinolones has shown a decreasing trend since 2013, due to the efforts to reduce the use of antibiotics in animals [45]. However, we could also interpret our data as a potential rising trend of the resistance of $P$. aeruginosa to ENR. Indeed, the high proportion of intermediate isolates $(45.8 \%$ or $41.7 \%$ based on the method used) with MICs values $(1-2 \mu \mathrm{g} / \mathrm{mL})$ close to the susceptible category may be represented by bacterial variants with a low level of resistance that could accelerate the evolution toward high and clinically relevant resistance $[47,48]$. Although we have not investigated the mechanisms underlying the intermediate/resistance response to ENR, we could suppose the combined role of efflux pump overexpression and mutational variations of DNA gyrase/topoisomerase IV [49].

No isolate was resistant to $\mathrm{CN}$ in the present study, probably reflecting the minimal use of aminoglycosides in dogs due to their severe side effects. In this sense, low percentages (about 4\%) of resistance to $\mathrm{CN}$ were detected worldwide in canine $P$. aeruginosa isolates [50-52], although some authors reported a higher presence of resistance, ranging from $26 \%$ [34] to $56 \%$ [53].

Among $\beta$-lactams antibiotics tested, a high percentage of isolates $(29.2 \%)$ showed intermediate profile against IMI with MIC values ranging from 2 to $6 \mu \mathrm{g} / \mathrm{mL}$. Carbapenem-resistant $P$. aeruginosa represents an emerging worldwide threat for human and animal health [54]. In the present study, none of these isolates were positive to the screening tests for $\beta$-lactamases and they were all susceptible to CAZ. The phenotype carbapenem-resistant/cephalosporin-susceptible represents an emerging profile in $P$. aeruginosa isolated from animal and human infection $[55,56]$. Therefore, resistance mechanisms different from the $\beta$-lactamase production have been investigated in the past years. In particular, the dysregulation of the efflux pumps system and the repression of the porin OprD expression represent two key mechanisms for the development of carbapenem-resistant $P$. aeruginosa in small animals [55]. However, carbapenemase-producing $P$. aeruginosa are characterized by higher MIC values in comparison with isolates lacking of this type of $\beta$-lactamase [34].

In the present study, 2 isolates $(8.3 \%)$ showed resistance to TZP while 4 isolates showed intermediate susceptibility $(16.7 \%)$, then revealing values comparable to what was reported by other authors [34,52]. As emerged by the screening tests for $\beta$-lactamases detection, $\mathrm{AmpC}$ was presumed to be the main mechanism responsible for the reduced susceptibility to TZP and also to CAZ in two isolates. The overexpression of AmpC $\beta$-lactamase in $P$. aeruginosa represents a common mechanism of resistance to the third-generation cephalosporins and to broad-spectrum penicillins [57], in association to other groups of $\beta$-lactamases, including ESBLs and MBLs that we have not detected by phenotype investigation.

Biofilm formation represents a well-investigated virulence factor of $P$. aeruginosa, promoting the persistence of the bacterial infection by the enhanced resistance to host immunity and antimicrobial drugs [58]. In the present study, most $P$. aeruginosa isolates resulted in being weak or intermediate biofilm producers, while the strong biofilm producers were derived exclusively from the ear canal samples. In this sense, biofilm production represents a common feature of $P$. aeruginosa involved in dog otitis, then facilitating the persistence of infection $[59,60]$.

The extracellular pathogenic factors play a key role in $P$. aeruginosa infection and the most investigated are represented by exotoxin A, phospholipase C, elastase, alkaline protease, and type III secretion system [61]. Few data are available in veterinary literature about the occurrence of these factors in P. aeruginosa clinical isolates from companion [62] and farm animals [63-65]. In the present study, a high occurrence was found for all the pathogenic markers that we investigated, suggesting the elevated virulence potential of the isolates, as well as reported in human clinical isolates [66-68].

All the factors we investigated have a key role in the invasion, colonization, and establishment of infection by $P$. aeruginosa. Elastase and alkaline protease are characterized by proteolytic activity against host extracellular matrix proteins [69]. Phospholipase C and exotoxin A exert the cytotoxic activity by hydrolysis of cell membrane lipids [70] and inhibition of cell protein synthesis [71], respectively. ExoS is a 
bifunctional enzyme of the type-III protein complex and it is involved in cytotoxic activity and in the stimulation of actin reorganization of cells [72]. In addition, these pathogenic elements favor the dissemination of $P$. aeruginosa through various mechanisms that negatively interfere with host immunity [73-77].

\section{Conclusion}

In the present study, the antimicrobial profiles of $P$. aeruginosa isolates from canine clinical samples were not characterized by an alarming resistance. However, the high presence of isolates with intermediate susceptibility to ENR could represent an early warning signal to monitor over time. Furthermore, the finding of reduced susceptibility to antibiotics not authorized for veterinary use, such as carbapenems, was indicative of the importance of the One Health approach to understand and to contrast the emerging diffusion of resistant pathogens. Moreover, the presence of isolates with strong ability to produce biofilm must be taken into account in the interpretation of the antimicrobial susceptibility profile. Besides, the high prevalence of the extracellular pathogenic factors was indicative of the potential virulence of the isolates.

\section{Authors' Contributions}

JH: Laboratory work, data analysis, and writing of the manuscript. FM: Planning of the study, laboratory work, data analysis, and writing of the manuscript. CED: Design, analysis, and interpretation of the molecular biology data and revision of the manuscript. GA: Sample collection and critical revision of the manuscript. GM: Critical revision of the manuscript. PG: Sample collection. PGT: Data analysis and critical revision of the manuscript. All authors read and approved the final manuscript.

\section{Acknowledgments}

The present study has been carried out in the framework of the Project "Demetra" (Dipartimenti di Eccellenza 2018-2022, CUP_C46C18000530001), funded by the Italian Ministry for Education, University and Research. The authors would like to thank Dr. Flavio Dimitri Cicci and the staff of the Veterinary Clinic "Saline" for their support in the collection of the clinical samples.

\section{Competing Interests}

The authors declare that they have no competing interests.

\section{Publisher's Note}

Veterinary World remains neutral with regard to jurisdictional claims in published institutional affiliation.

\section{References}

1. Grosso-Becerra, M.V., Santos-Medellìn, C., GonzàlezValdez, A., Mendèz, J.L., Delgado, G., Morales-Espinosa, R., Servìn-Gonzàlez, L., Alcaraz, L.D. and Soberòn-Chàvez, G.
(2014) Pseudomonas aeruginosa clinical and environmental isolates constitute a single population with high phenotypic diversity. BMC Genomics, 15: 318.

2. Ludwig, C., de Jong, A., Moyaert, H., El Garch, F., Janes, R., Klein, U., Morrisey, I., Thiry, J. and Youala, M. (2016) Antimicrobial susceptibility monitoring of dermatological bacterial pathogens isolated from diseased dogs and cats across Europe (ComPath results). J Appl. Microbiol., 121(5): 1254-1267.

3. Hall, J.L., Holmes, M.A. and Baines, S.J. (2013) Prevalence and antimicrobial resistance of canine urinary tract pathogens. Vet. Record, 173(22): 549.

4. Yoshimura, F. and Nikaido, H. (1982) Permeability of Pseudomonas aeruginosa outer membrane to hydrophilic solutes. J. Bacteriol., 152(2): 636-642.

5. Aeschlimann, J.R. (2003) The role of multidrug efflux pumps in the antibiotic resistance of Pseudomonas aeruginosa and other gram-negative bacteria. Insights from the Society of Infectious Diseases Pharmacists. Pharmacotherapy, 23(7): 916-924.

6. Bagge, N., Ciofu, O., Hentzer, M., Campbell, J.I.A., Givskov, M. and Hoiby, N. (2002) Constitutive high expression of chromosomal -lactamase in Pseudomonas aeruginosa caused by a new insertion sequence (IS1669) located in ampD. Antimicrob. Agents Chemother., 46(11): 3406-3411.

7. Pan, Y., Xu, Y., Wang, Z., Fang, Y. and Shen, J. (2016) Overexpression of MexAB-OprM efflux pump in carbapenem-resistant Pseudomonas aeruginosa. Arch. Microbiol., 198(6): 565-571.

8. Li, H., Luo, Y.F., Williams, B., Blackwell, T.S. and Xie, C.M. (2012) Structure and function of OprD protein in Pseudomonas aeruginosa: From antibiotic resistance to novel therapies. Int. J. Med. Microbiol., 302(2): 63-68.

9. Nakano, M., Deguchi, T., Kawamura, T., Yasuda, M., Kimura, M., Okano, Y. and Kawada, Y. (1997) Mutations in the gyrA and parC genes in fluoroquinolone-resistant clinical isolates of Pseudomonas aeruginosa. Antimicrob. Agents Chemother., 41(10): 2289-2291.

10. Zhao, W.H. and Hu, Z.Q. (2010) Beta-lactamases identified in clinical isolates of Pseudomonas aeruginosa. Crit. Rev. Microbiol., 36(3): 245-258.

11. Lupo, A., Haenni, M. and Madec, J.Y. (2018) Antimicrobial resistance in Acinetobacter spp. and Pseudomonas spp. In: Schwarz, S., Cavaco, L.M. and Shen, J., editors. Antimicrobial Resistance in Bacteria from Livestock and Companion Animals. ASM Press, Washington DC, USA. p377-393.

12. Fernandes, M.R., Sellera, F.P., Moura, Q., Carvalho, M.P.N., Rosato, P.N., Cerdeira, L. and Lincopan, N. (2018) Zooanthroponotic transmission of drug-resistant Pseudomonas aeruginosa, Brazil. Emerg. Infect. Dis., 24(6): 1160-1162.

13. Clinical Laboratory Standard Institute. (2020) Performance Standards for Antimicrobial Susceptibility Testing. $30^{\text {th }}$ ed. CLSI Supplement M100, Clinical and Laboratory Standards Institute, Wayne, PA.

14. Clinical Laboratory Standard Institute. (2018) Performance Standards for Antimicrobial Disk and Dilution Susceptibility Tests for Bacteria Isolated From Animals. $4^{\text {th }}$ ed. CLSI Supplement VET08, Clinical and Laboratory Standards Institute, Wayne, PA.

15. Clinical Laboratory Standard Institute. (2018) Performance Standards for Antimicrobial Disk and Dilution Susceptibility Tests for Bacteria Isolated From Animals. $5^{\text {th }}$ ed. CLSI Standard VET01, Clinical and Laboratory Standards Institute, Wayne, PA.

16. Clinical Laboratory Standard Institute. (2008) Development of In Vitro Susceptibility Testing Criteria and Quality Control Parameters for Veterinary Antimicrobial Agents; Approved Guideline. $3^{\text {rd }}$ ed. CLSI Document M37-A3, Clinical and Laboratory Standards Institute, Wayne, PA. 
17. Reuland, E.A., Hays, J.P., de Jongh, D.M.C., Abdelrehim, E., Willemsen, I., Kluytmans, J.A.J., Savelkoul, P.H.M., Vandenbroucke-Grauls, C.M.J. and al Naiemi, N. (2014) Detection and occurrence of plasmid-mediated AmpC in highly resistant Gram-negative rods. PLoS One, 9(3): e91396.

18. Jiang, X., Zhang, Z., Li, M., Zhou, D., Ruan, F. and Lu, Y. (2006) Detection of extended-spectrum beta-lactamases in clinical isolates of Pseudomonas aeruginosa. Antimicrob. Agents Chemother., 50(9): 2990-2995.

19. Yong, D., Lee, K., Yum, J.H., Shin, H.B., Rossolini, G.M. and Chong, Y. (2002) Imipenem-EDTA disk method for differentiation of metallo- $\beta$-lactamase-producing clinical isolates of Pseudomonas spp. and Acinetobacter spp. J. Clin. Microbiol., 40(10): 3798-3801.

20. Stepanovic, S., Vukovic, D., Dakic, I., Savic, B. and Svabic-Vlahovic, M. (2000) A modified microtiter-plate test for quantification of staphylococcal biofilm formation. J. Microbiol. Methods, 40(2): 175-179.

21. Schubiger, C.B., Hoang, K.H.T. and Hase, C.C. (2020) Sodium antiporters of Pseudomonas aeruginosa in challenging conditions: Effects in growth, biofilm formation, and swarming motility. J. Genet. Eng. Biotechnol., 18(1): 4.

22. Mittal, R., Sharma, S., Chhibber, S., Aggarval, S., Gupta, V. and Harjai, K. (2010) Correlation between serogroup, in vitro biofilm formation and elaboration of virulence factors by uropathogenic Pseudomonas aeruginosa. FEMS Immunol. Med. Microbiol., 58(2): 237-243.

23. Lanotte, P., Watt, S., Mereghetti, L., Dartiguelongue, N., Rastegar-Lari, A., Goudeau, A. and Quentin, R. (2004) Genetic features of Pseudomonas aeruginosa isolates from cystic fibrosis patients compared with those of isolates from other origins. J. Med. Microbiol., 53(1): 73-81.

24. Zhu, H., Bandara, R., Conibear, T.C.R., Thuruthyil, S.J., Rice, S.A., Kjelleberg, S., Givskov, M. and Willcox, M.D.P. (2004) Pseudomonas aeruginosa with LasI quorum-sensing deficiency during corneal infection. Invest. Ophthalmol. Vis. Sci., 45(6): 1897-1903.

25. Gellatly, S.A. and Hancock, R.E.W. (2013) Pseudomonas aeruginosa: New insights into pathogenesis and host defenses. Pathog. Dis., 67(3): 159-173.

26. Lister, P.D., Wolter, D.J. and Hanson, N.D. (2009) Antibacterial-resistant Pseudomonas aeruginosa: Clinical impact and complex regulation of chromosomally encoded resistance mechanisms. Clin. Microbiol. Rev., 22(4): 582-610.

27. Wong, C., Epstein, S.E. and Westropp, J.L. (2015) Antimicrobial susceptibility patterns in urinary tract infections in dog (2010-2013). J. Vet. Intern. Med., 29(4): 1045-1052.

28. Ball, K.R., Rubin, J.E., Chirino-Trejo, M. and Dowling, P.M. (2008) Antimicrobial resistance and prevalence of canine uropathogens at the Western college of veterinary medicine veterinary teaching hospital, 2002-2007. Can. Vet. J., 49(10): 985-990.

29. Punia, M., Kumar, A., Charaya, G. and Kumar, T. (2018) Pathogens isolated from clinical cases of urinary tract infection in dogs and their antibiogram. Vet. World, 11(8): 1037-1042.

30. Petersen, A.D., Walker, R.D., Bowman, M.M., Schott, H.C. and Rosser, E.J. (2002) Frequency of isolation and antimicrobial susceptibility patterns of Staphylococcus intermedius and Pseudomonas aeruginosa isolates from canine skin and ear samples over a 6-year period (1992-1997). J. Am. Anim. Hosp. Assoc., 38(5): 407-413.

31. Colombini, S., Mechant, S.R. and Hosgood, G. (2008) Microbial flora and antimicrobial susceptibility patterns from dogs with otitis media. Vet. Dermatol., 11(4): 235-239.

32. Chaudhary, A.K., Kumar, A. and Shrivastva, M. (2019) Study on prevalence and resistance patterns of bacterial pathogens isolated from canine pyoderma. Int. J. Curr. Microbiol. Appl. Sci., 8(1): 2305-2311.
33. Pintaric, S., Matanovic, K. and Martinec, B.S. (2017) Fluoroquinolone susceptibility in Pseudomonas aeruginosa isolates from dogs comparing disk diffusion and microdilution methods. Vet. Ahriv, 87(3): 291-300.

34. Hyun, J.E., Chung, T.H. and Hwang, C.Y. (2018) Identification of VIM-2 metallo- $\beta$-lactamase-producing Pseudomonas aeruginosa isolated from dogs with pyoderma and otitis in Korea. Vet. Dermatol., 29(3): 186-e68.

35. Wildermuth, B.E., Griffin, C.E., Rosenkrantz, W.S. and Boord, M.J. (2007) Susceptibility of Pseudomonas isolates from the ears and skin of dogs to enrofloxacin, marbofloxacin, and ciprofloxacin. J. Am. Anim. Hosp. Assoc., 43(6): 337-341.

36. Malayeri, H.Z., Jamshidi, S. and Salehi, T.Z. (2010) Identification and antimicrobial susceptibility patterns of bacteria causing otitis externa in dogs. Vet. Res. Commun., 34(5): 435-444.

37. Beier, R.C., Foley, S.L., Davidson, M.K., White, D.G., McDermott, P.F., Bodeis-Jones, S., Zhao, S., Andrews, K., Crippen, T.L., Sheffield, C.L., Poole, T.L., Anderson, R.C. and Nisbet, D.J. (2014) Characterization of antibiotic and disinfectant susceptibility profile among Pseudomonas aeruginosa veterinary isolates recovered during 1994-2003. J. Appl. Microbiol., 118(2): 326-342.

38. Joyce, L.F., Downes, J., Stockman, K. and Andrew, J.H. (1992) Comparison of five methods, including the PDM epsilometer test (E test), for antimicrobial susceptibility testing of Pseudomonas aeruginosa. J. Clin. Microbiol., 30(10): 2709-2713.

39. Burns, J.L., Saiman, L., Whittier, S., Larone, D., Krzewinski, J., Liu, Z., Marshall, S.A. and Jones, R.N. (2000) Comparison of agar diffusion methodologies for antimicrobial susceptibility testing of Pseudomonas aeruginosa isolates from cystic fibrosis patients. J. Clin. Microbiol., 38(5): 1818-1822.

40. Di Bonaventura, G., Ricci, E., Della Loggia, N., Catamo, G. and Piccolomini, R. (1998) Evaluation of the E test for antimicrobial susceptibility testing of Pseudomonas aeruginosa isolates from patients with long-term bladder catheterization. J. Clin. Microbiol., 36(3): 824-826.

41. World Health Organization. (2019) Model List of Essential Medicines. $21^{\text {st }}$ ed. World Health Organization, Geneva.

42. Awosile, B.B., McClure, J.T., Saab, M.E. and Heider, L.C. (2018) Antimicrobial resistance in bacteria isolated from cats and dogs from the Atlantic provinces, Canada from 1994-2013. Can. Vet. J., 59(8): 885-893.

43. Mekic, S., Matanovic, K. and Seol, B. (2011) Antimicrobial susceptibility of Pseudomonas aeruginosa isolates from dogs with otitis externa. Vet. Rec., 169(5): 125.

44. Vingopoulou, E.I., Delis, G.A., Batzias, G.C., Kaltsogianni, F., Koutinas, A., Kristo, I., Pournaras, S., Saridomichelakis, M.N. and Siarkou, V.I. (2018) Prevalence and mechanisms of resistance to fluoroquinolones in Pseudomonas aeruginosa and Escherichia coli isolates recovered from dogs suffering from otitis in Greece. Vet. Microbiol., 213: 102-107.

45. Bourèly, C., Cazeau, G., Jarrige, N., Leblond, A., Madec, J.Y., Haenni, M. and Gay, E. (2019) Antimicrobial resistance patterns of bacteria isolated from dogs with otitis. Epidemiol. Infect., 147: e121.

46. De Martino, L., Nocera, F.P., Mallardo, K., Nizza, S., Masturzo, E., Fiorito, F., Iovane, G. and Catalanotti, P. (2016) An update on microbiological causes of canine otitis externa in Campania region, Italy. Asian Pac. J. Trop. Biomed., 6(5): 384-389.

47. Wistrand-Yuen, E., Knopp, M., Hjort, K., Koskiniemi, S., Berg, O.G. and Andersson, D.I. (2018) Evolution of highlevel resistance during low-level antibiotic exposure. Nat. Commun., 9(1): 1599.

48. Baquero, F. (2001) Low-level antibacterial resistance: A gateway to clinical resistance. Drug Resist. Updat., 4(2): 93-105. 
49. Harada, K., Arima, S., Niina, A., Kataoka, Y. and Takahashi, T. (2012) Characterization of Pseudomonas aeruginosa isolates from dogs and cats in Japan: Current status of antimicrobial resistance and prevailing resistance mechanisms. Microbiol. Immunol., 56(2): 123-127.

50. Park, Y., Oh, J., Park, S., Sum, S., Song, W., Chae, J. and Park, H. (2020) Antimicrobial resistance and novel mutations detected in the gyrA and parC genes of Pseudomonas aeruginosa strains isolated from companion dogs. BMC Vet. Res., 16: 111.

51. Yukawa, S., Tsuyuki, Y., Sato, T., Fukuda, A., Usui, M. and Tamura, Y. (2017) Antimicrobial resistance of Pseudomonas aeruginosa isolated from dogs and cats in primary veterinary hospitals in Japan. Jpn. J. Infect. Dis., 70(4): 461-463.

52. Arais, L.R., Barbosa, A.V., Carvalho, C.A. and Cerqueira, A.M.F. (2016) Antimicrobial resistance, integron carriage, and gyrA and gyrB mutations in Pseudomonas aeruginosa isolated from dogs with otitis externa and pyoderma in Brazil. Vet. Dermatol., 27(2): 113-7e31.

53. Haenni, M., Hocquet, D., Ponsin, C., Cholley, P., Guyeux, C., Madec, J.Y. and Bertrand, X. (2015) Population structure and antimicrobial susceptibility of Pseudomonas aeruginosa from animal infections in France. BMC Vet. Res., 11: 9.

54. Gentilini, F., Turba, M.E., Pasquali, F., Mion, D., Romagnoli, N., Zambon, E., Terni, D., Peirano, G., Pitout, J.D.D., Parisi, A., Sambri, V. and Zanoni, R.G. (2018) Hospitalized pets as a source of carbapenem-resistance. Front. Microbiol., 9: 2872.

55. Haenni, M., Bour, M., Chatre, P., Madec, J.Y., Plesiat, P. and Jeannot, K. (2017) Resistance of animal strains of Pseudomonas aeruginosa to carbapenems. Front. Microbiol., 8: 1847.

56. Campana, E.H., Xavier, D.E., Petrolini, F.V., CordeiroMoura, J.R., de Araujo, M.R. and Gales, A.C. (2017) Carbapenem-resistant and cephalosporin-susceptible: Aworrisome phenotype among Pseudomonas aeruginosa clinical isolates in Brazil. Braz. J. Infect. Dis., 21(1): 57-62.

57. Cabot, G., Ocampo-Sosa, A.A., Tubau, F., Macia, M.D., Rodriguez, C., Moya, B., Zamorano, L., Suàrez, C., Pena, C., Martinez, L.M. and Oliver, A. (2011) Overexpression of AmpC and efflux pumps in Pseudomonas aeruginosa isolates from bloodstream infections: prevalence and impact on resistance in a Spanish multicenter study. Antimicrob. Agents Chemother., 55(5): 1906-1911.

58. Olivares, E., Badel-Berchoux, S., Provot, C., Prèvost, G., Bernardi, T. and Jehl, F. (2020) Clinical impact of antibiotics for the treatment of Pseudomonas aeruginosa biofilm infections. Front. Microbiol., 10: 2894.

59. Chan, W.Y., Hickey, E.E., Page, S.W., Trott, D.J. and Hill, P.B. (2019) Biofilm production by pathogens associated with canine otitis externa, and the antibiofilm activity of ionophores and antimicrobial adjuvants. J. Vet. Pharmacol. Ther., 42(6): 682-692.

60. Pye, C.C., Yu, A.A. and Weese, J.S. (2013) Evaluation of biofilm production by Pseudomonas aeruginosa from canine ears and the impact of biofilm on antimicrobial susceptibility in vitro. Vet. Dermatol., 24(4): 446-449.

61. Westman, E.L., Matewish, J.M. and Lam, J.S. (2010). Pseudomonas. In: Gyles, C.L., Prescott, J.F., Songer, J.G. and Thoen, C.O., editors. Pathogenesis of Bacterial Infections in Animals. Ch. 23. Wiley-Blackwell, Ames, Iowa, USA. p443-468.

62. Ledbetter, E.C., Mun, J.J., Kowbel, D. and Fleiszig, S.M.J. (2009) Pathogenic phenotype and genotype of Pseudomonas aeruginosa isolates from spontaneous canine ocular infections. Invest. Ophthalmol. Vis. Sci., 50(2): 729-736.

63. Hassan, W.H., Ibrahim, A.M.K., Shany, S.A.S. and Salam, H.S.H. (2020) Virulence and resistance determinants in Pseudomonas aeruginosa isolated from pericarditis in diseased broiler chickens in Egypt. J. Adv. Vet. Anim. Res., 7(3): 452-463.

64. Dapgh, A.N., Hakim, A.S., Abouelhag, H.A., Abdou, A.M. and Elgabry, E.A. (2019) Detection of virulence and multidrug resistance operons in Pseudomonas aeruginosa isolated from Egyptian Baladi sheep and goat. Vet. World, 12(10): 1524-1528.

65. Banerjee, S., Batabyal, K., Joardar, S.N., Isore, D.P., Dey, S., Samanta, I., Samanta, T.K. and Murmu, S. (2017) Detection and characterization of pathogenic Pseudomonas aeruginosa from bovine subclinical mastitis in West Bengal, India. Vet. World, 10(7): 738-742.

66. Rodrigues, Y.C., Furlaneto, I.P., Maciel, A.H.P., Quaresma, A.J.P., de Matos, E.C.O., Conceição, M.L., Vieira, M.C.D., Brabo, G.L.D., Sarges, E.D.S., Lima, L.N.G. and Lima, K.V.B. (2020) High prevalence of atypical virulotype and genetically diverse background among Pseudomonas aeruginosa isolates from a referral hospital in the Brazilian Amazon. PLoS One, 15(9): e0238741.

67. Badamchi, A., Masoumi, H., Javadinia, S., Asgarian, R. and Tabatabaee, A. (2017) Molecular detection of six virulence genes in Pseudomonas aeruginosa isolates detected in children with urinary tract infection. Microb. Pathog., 107: 44-47.

68. Faraji, F., Mahzounieh, M., Ebrahimi, A., Fallah, F., Teymournejad, O. and Lajevardi, B. (2016) Molecular detection of virulence genes in Pseudomonas aeruginosa isolated from children with cystic fibrosis and burn wounds in Iran. Microb. Pathog., 99: 1-4.

69. Galdino, A.C.M., Branquinha, M.H. and Santos, A.L.S. (2017) Pseudomonas aeruginosa and its 4 arsenal of proteases: Weapons 5 to battle the host. In: Chakraborti, S. and Dhalla, N., editors. Pathophysiological Aspects of Proteases. Ch. 16. Springer, Switzerland.

70. Vasil, M.L., Stonehouse, M.J., Vasil, A.I., Wadsworth, S.J., Goldfine, H., Bolcome, R.E $3^{\text {rd }}$. and Chan, J. (2009) A complex extracellular sphingomyelinase of Pseudomonas aeruginosa inhibits angiogenesis by selective cytotoxicity to endothelial cells. PLoS Pathog., 5(5): e1000420.

71. Wolf, P. and Elsässer-Beile, U. (2009) Pseudomonas exotoxin A: From virulence factor to anticancer agent. Int. J. Med. Microbiol., 299(3): 161-176.

72. Barbieri, J.T. (2000) Pseudomonas aeruginosa exoenzyme $\mathrm{S}$, a bifunctional Type-III secreted cytotoxin. Int. $J$. Med. Microbiol., 290(4-5): 381-387.

73. Garai, P., Berry, L., Moussouni, M., Bleves, S. and BlancPotard, A.B. (2019) Killing from the inside: Intracellular role of T3SS in the fate of Pseudomonas aeruginosa within macrophages revealed by mgtC and oprF mutants. PLoS Pathog., 15(6): e1007812.

74. Casilag, F., Lorenz, A., Krueger, J., Klawonn, F., Weiss, S. and Häussler S. (2016) The LasB elastase of Pseudomonas aeruginosa acts in concert with alkaline protease AprA to prevent flagellin-mediated immune recognition. Infect. Immun., 84(1): 162-171.

75. Laarman, A.J., Bardoel, B.W., Rujken, M., Fernie, J., Milder, F.J., van Striijp, J.A.G. and Rooijakkers, S.H.M. (2012) Pseudomonas aeruginosa alkaline protease blocks complement activation via the classical and lectin pathways. J. Immunol., 188(1): 386-393.

76. Kuang, Z., Hao, Y., Walling, B.E., Jeffries, J.L., Ohman, D.E. and Lau, G.W. (2011) Pseudomonas aeruginosa Elastase provides an escape from phagocytosis by degrading the pulmonary surfactant protein-A. PLoS One, 6(11): e27091.

77. Terada, L.S., Johansen, K.A., Nowbar, S., Vasil, A.I. and Vasil, M.L. (1997) Pseudomonas aeruginosa hemolytic phospholipase C suppresses neutrophil respiratory burst activity. Infect. Immun., 67(5): 2371-2376. 